\title{
Discovering the Stock Tweet Attribute. A Case Study @IDX_BEI
}

\author{
Dewi Anggraini \\ Department of Accounting, Universitas Mercu Buana, Indonesia
}

\begin{abstract}
Users spends most of his time to use social media services, therefore social media data analysis can provide a deeper understanding about the consumer behavior, the data can be utilized for a variety of purposes, one of which was finance. As an example Thomson Reuter Eikon and Bloomberg provide financial services that use tweet for financial analysis. Therefore, the purpose of this research is to discover the @IDX BEI stock tweet attribute. This research will explore the @IDX_BEI attribute using data obtained from the tweet of the twitter account@IDX_BEI for the period July to December 2016.
\end{abstract}

Keywords: Stock Tweet, Exploratory Factor Analysis, @IDX_BEI

DOI: $10.7176 /$ RJFA/10-24-05

Publication date: December $31^{\text {st }} 2019$

\section{Research Background}

Social media like twitter, facebook generates a blast of unstructured opinions (unstructured text) which has its benefits and value in the decision-making process (Montoyo, MartíNez-Barco, \& Balahur, 2012). Social media data is called microblogging data that can be used to estimate the variables such as stock market returns, volatility and the number of shares traded with various indicators and portfolios. The results of the research (Oliveira, Cortez, \& Areal, 2017) proves that the microblogging data expert system useful for the financial sector, the data able to predict the behavior of the stock market and provides an alternative that is worth to build a useful survey measurements, quick, inexpensive and can be used every day for each transaction in the stock market.

Users of social media, Internet, and Web 2.0 generates data which is very much important for consumer profiling (Fan \& Gordon, 2014). This 2.0 phenomenon promote the products from the internet, the terminology that is believed to be useful because users can more easily deliver its products besides their interaction with others and allow product promotion through the website. In the context of stock trading, social media provide information and also the data source that can be used by internet users in the decision making process.

Social media are already used as proxy of the stock (Li et al., 2014), their research on financial behavior found stock investors sentiment can be measured to predict stock market movements. This technique conducted by taking the mood of the public from the interactive investor conversation in social media, specific company news influence the behavior of the interactive investor. From these observations, concluded there is predictive capability to forecast the price of the stock market. The application of social media data became attractive because the activity of investors or market shares can be read from the activities in social media. So, if we want to obtain the initial prediction of stock market movements, social media data can be estimated to forecast the future.

Blog, tweet and Facebook can also predict the future in the context of finance. (Kumar \& Ravi, 2016) stated that data processing technique can provide useful information in the financial sector, its application can be used to predict currency rates, and also predicted the stock market to see the response of consumers.

Specifically, the celebrities can also be observation and influence the stock market. The celebrities included here are those people who are considered to have the credibility and value of the information in the industry (Zhang, An, Feng, \& Jin, 2017). Their posts can affect the stock market while the regular people had no power of prediction. The conclusions of this experiment that the tweet delivered to the public through social media are information that can affect the future.

News media delivered by the Google news can also observed to reflect the movement of the stock market (Byström, 2016). Stock market news collected consists of two languages which are United Kingdom and Chinese language, results from the Google news category found that there is a relationship between news posted and the movement of the stock market. Therefore, we can conclude that the news posted in social media will also affect the movement in the stock market.

(Lansley \& Longley, 2016) also stated that social media data are data which can be an alternative proxy behavior in society. Opinion delivered in the social media community became a Corpus or documents, so we can also see the History of the conversation in the twitter.

(Chae, 2015) stated that the survey can also be used to segment your market or classify existing people's interest in the financial markets. Therefore business in the future required knowledge toward selected groups, therefore the benefit of data for the stock market becomes crucial to be discussed and examined further. 


\section{Theoretical Review}

(Tu, Yang, Cheung, \& Mamoulis, 2018) Twitter is a channel of information that will be used by investors. Study conducted found that the information is able to predict the future. (Mazboudi \& Khalil, 2017) conduct a research on the push technology, the research conclude that the sentiment delivered in social media affect the activity in the stock market.

(García, 2016) also stated that social media can be used to view the daily movement and polarity of the stock market.

Social media is also the place to express views and perspective. Analysis of the expression given by academia researchers as well as by the stock market practitioner apparently can influence the decision-making process (Khanna, Moses, \& Nirmala, 2018).

Online articles and News Articles can also increase the dynamic prediction, as submitted by the observers on condition of the economy or stocks. These predictions published in an online news release will affect the movement of the stock market (Chen \& Chen, 2017).

The same thing also delivered about predictive ability to influence the stock prices of the existing post information on the internet (Al Nasseri, Tucker, \& de Cesare, 2015). This statement is a special test on how tweet or stock market related and turned out to have a force that is referred to as the power of the collective. This research uses the terminology existing tweet and see whether this terminology is affecting the performance of the stock, therefore the tweet are beneficial and also affects the movement of stock trading activity in the stock market.

\section{Research Method}

The method to manage data in the form of tweets requires a different approach compare with the ordinal or numerical data. Tweet posted by twitter account need to be managed with the textual processing software, therefore we utilized and optimizing the decision-making process. This research seeks to observe data within a longer time interval. Longer observation can explore the holistic activity of the @IDX BEI twitter. Therefore the data preparation required several stages.

The first process begins with the collection of primary data tweet, furthermore the data cleaned, through the process of stemming and lemmatization. Finally, the exploratory conducted to obtain the attribute sentiments from @IDX BEI. Data exploration of tweet during the period July to December 2016. Exploratory analysis conducted by using the program QDA Miner (Lewis \& Maas, 2007). The program will expose the dominant topics in a tweet on the dataset (Silver \& Lewins, 2014). The dominant topic reflects the activities conducted and delivered by twitter@IDX_BEI.

This technique support researchers to organize and analyze large data. Data from social media delivered by many users and many activities. Social media data processing is more difficult to conduct manually, therefore with the software analysis, researchers can obtain faster results (Nugroho, 2018a) (Nugroho \& Sihite, 2016). However, it should be noted that the data is not structured so that researchers need to carefully conduct data processing before data analysis (Nugroho, 2017) (Sihite \& Nugroho, 2017) (Nugroho \& Sihite, 2015a). All data need to be checked before being processed further, there is possibility of repeated data, it's likely there are also incomplete data information, therefore data checking needed before the analysis (Sihite \& Nugroho, 2018) (Nugroho, 2018b) (Nugroho \& Sihite, 2015b) (Nugroho \& Sihite, 2015c) (Nugroho \& Sihite, 2015).

This research is an exploratory research with longitudinal data tweet. In the exploratory research, the data used is the primary data obtained from the twitter account, the tweet sample since the period of July to December 2016. The selection conducted to express the variety of stock market attribute from @IDX_BEI twitter. The approach to analyze unstructured data and dig up useful information from these data is the goal of this research. Hopefully through the analysis conducted, researchers and practitioners of the stock market can get an alternative way to dig out information from the tweet data available in the market.

\section{Results and Discussion}

Total tweet collected during the period of July to December 2016 are 1088 tweet. These-tweet further organized for the top 10 tweet frequency, one of the top 10 tweet Yuknabungsaham this is a frequency program of activities to promote saving in stocks that are targeted to the younger generation. In the twitter, @idx_bei promote the activities Yuknabungsaham in interesting ways, this activity is organized by presenting a phenomenal Indonesia artist, @idx bei also shows the results of a survey regards to the public reason for saving stocks, additionally @idx_bei also opened an online chat to make it easy for the potential investors who would like to ask for further question. This application support an easy communication, anywhere and anytime. There is also the JCI (Jakarta Composite Index), which also occupy the Top 10 keywords delivered over the period of observation. These results convey that the information about the@idx_bei twitter activity and the BEI movement and the frequency of trading (buying and selling shares). One example of this is the JCI index posted on 12 July 2016 when the JCI closed in 5,099.44 the highest position of the index within the year 2016. 
Furthermore, the hashtags results shows that the yuknabungsaham also occupy the 1st most frequent hashtags (218). There is also activities promoted by the @idx bei which is the investival or festival of investment (121). Investival is the Indonesia Investment Festival organized by BEI cooperates with various parties a range of exciting events conducted like a talkshow, quis, doorprize, games. One of the topics discussed in the investival talk-show is about financial planning. Investival also develop activities in some cities and universities, like the University of North Sumatra (Medan), University of Lampung, Suzuya Mall (Banda Aceh). Investival is the persuasive tactics of the BEI to influence society to become investors.

@idx_bei also conduct the activities of the tax amnesty (91). In this hashtag, @idx_bei deliver information about the taxes and information from Directorate General of Tax Republic of Indonesia. There is also info about the opening of the tax amnesty clinics organized by BEI. BEI also actively organized a workshop for the journalists in various cities, including Makassar. These activities conducted to discuss the relevant topics of the stock market, such as the tax amnesty socialization and capital market socialization.

aidx bei also deliver the hashtags Idxgoodnews which delivered good news from stock trading in Indonesia as well as going public with the activities of IPO (Initial Public Offering) companies in Indonesia. In the hashtag Idxgoodnews, JCI also delivered the ever-increasing performance every time, and the performance always broke the record of the transaction.

Mentions by the @idx bei consist of stakeholders in the financial industry in particular stock i.e. OJK Indonesia (48), kemenkeuri (36), ditjenpajakri (28), kemenbumn (16), as well as stock company mncsecurities (17) and stock observers talktophillip (11). The contents of the mention are the activities conducted by these companies, for example is the mention of @idx_bei to the @kemenkeuri to pass along the tax amnesty.

Furthermore, in the twitter @idx bei also presents information about the tax amnesty, the background, and the benefits. There is also a twitter content that tweet @KemenBUMN on congratulations to the company that became the Best IDX Blue chip company 2016, i.e. pt. Aneka Tambang (Persero). IDX Best Blue is the title given by the BEI to companies that have best performance growth for a period of one year. This is becomes an indicator of BEI IDX to determine the winner of the Best Blue which traded most by the investors. In addition, @idx_bei also announced the winners of the ARA 2015. ARA stands for Annual Report Award, ARA have been held 16 times up to the year 2016. There are 11 categories in this award category Financial State Owned Enterprise Listed (PT BNI), Non-financial State Owned Enterprise Listed (PT Antam) State-Owned Enterprise, Financial Non-Listed (PT. Asuransi Jasindo), category of Non-Financial Non-Listed State-Owned Enterprises (Perum Peruri). Other category i.e. Private Financial Categories Listed (PT. CIMB Niaga), category of NonFinancial Private Listed (PT. Unilever Indonesia), category of Non-Financial Private Listed (PT. Sampoerna), the category of Private Non-Financial Non-Listed (PT. Semen Tonasa). As for the last three categories is owned companies listed (Bank DKI), Local non-Listed (MRT Jakarta), and categories of pension funds (Dana Pensiun Telkom).

In addition, there is mention that related to the @mncsecurities which is about the inauguration of the Gallery at the various universities for BEI investment gallery, such as the inauguration of the 205 BEI investment Gallery at the University of Papua, Geissler Ottow, and inauguration for the 49th Gallery BEI in STIE Nusantara Sangatta.

There are also exciting activities presented by the BEI in the twitter with@DitjenPajakRI. One of the activities is a workshop of journalists in various cities, such as BEI Manado and DJP United Regional about the tax amnesty and the capital markets. BEI Riau is teaming up with KPP Pratama to conduct a consultation on the tax amnesty. And the tax amnesty socialization activities for Pacific Capital investors Investment that also works with DitjenPajakRI. BEI Kendari and DitjenPajakRI also held a workshop of journalists about the socialization One Stop Service tax amnesty.

There are still many other cities that will made the investment gallery and other activities, such as the journalist workshop in Denpasar, Padang, with varieties of different topics. There is also a socialization about the development of Indonesia's economic policy by the Director-General of @DJPPRkemenkeu. Stakeholders shows anyone who presented the views of the parties as well as its activities in the twitter @idx bei. Therefore, these results indicate that@idx bei is still only a financial news channel.

The results of the exploratory factor analysis for the period July to December 2016 produce 57 topics with eigen value above 1. 57 this topic can be grouped into 3 parts, which are a group of topics that convey information about the stock endorsing the stakeholders, groups of topics that indicate the potential for future stock performance, as well as a group of topics that conveys the information of activities IDX.

The majority of the topics are formed from cluster analysis, this information related activities such as BEI tax amnesty activity, the inauguration of the Gallery, BEI investment service socialization such as ipot, the activities of Director BEI Tito Sulistyo, the information activities of the IPO, the opening of the branch office opening trade, BEI, and broadcasting the talkshow at idx channel. Another group of topics delivered by @idx bei is an activity related to the stakeholders such as the Ministry of finance, BEI OJK, Additionally, there are TICMI, KSEI, MNC Securities, KPD. The majority of the stakeholders activities delivered by @idx_bei are 
the government agencies. Nevertheless only a few securities companies as well as educational institutions and observers who delivered his views at@idx bei.

Another interesting topic group indicate the performance of stocks in the future. This group consists of the trade, the frequency of exposure work plan of a company that will Go Public, performance shares when IPO and post IPO, performance of JCI, the influx of foreign investment funds, loan performance bonds, as well as economic projections. In the twitter account, @idx_bei delivered some information activities that relate to the topic of Go Public. Among them, namely the Investor Summit and Capital Market Expo 2016 and the Inauguration of Go Public information center in 4 cities in Indonesia. There are also mentions that inform and engage the community to be a part in the Prodia Go Public company's on the re-tweet by @idx_bei.

BEI also inform about the IPO, it can be seen from the @idx_bei activities delivering to a number of funds from the issuance of shares of the IPO in the year 2016 or higher from the year 2015 that reached Rp. 12.1 trillion. Furthermore, there are information about the socialization of IPO organized in Jakarta Stock Exchange, Graha Niaga, and attended by more than 80 companies. Furthermore, BEI convey information about bonds. BEI note bonds and sukuk that reach 96.53 Trillion rupiah. There are also topics that discuss the definition of bond and its benefits. BEI also provides information on capital market daily, such as information about Mandiri Finance which issued bonds amounting to Rp 500 Billion on 09 June 2016, on the same date BEI also delivered a total emission of bonds reached Rp. 68.60 trillion. These topics can still be elaborated again into several groups, but these 3 Group still can be a representation of all tweet@idx bei. The findings of this research show that @idx_bei still deliver a few of the Indonesian stocks performance, since the majority of the information delivered are work plan and post the performance of stocks that Go Public (Figure 1).

Figure 1.@idx_bei Dendogram

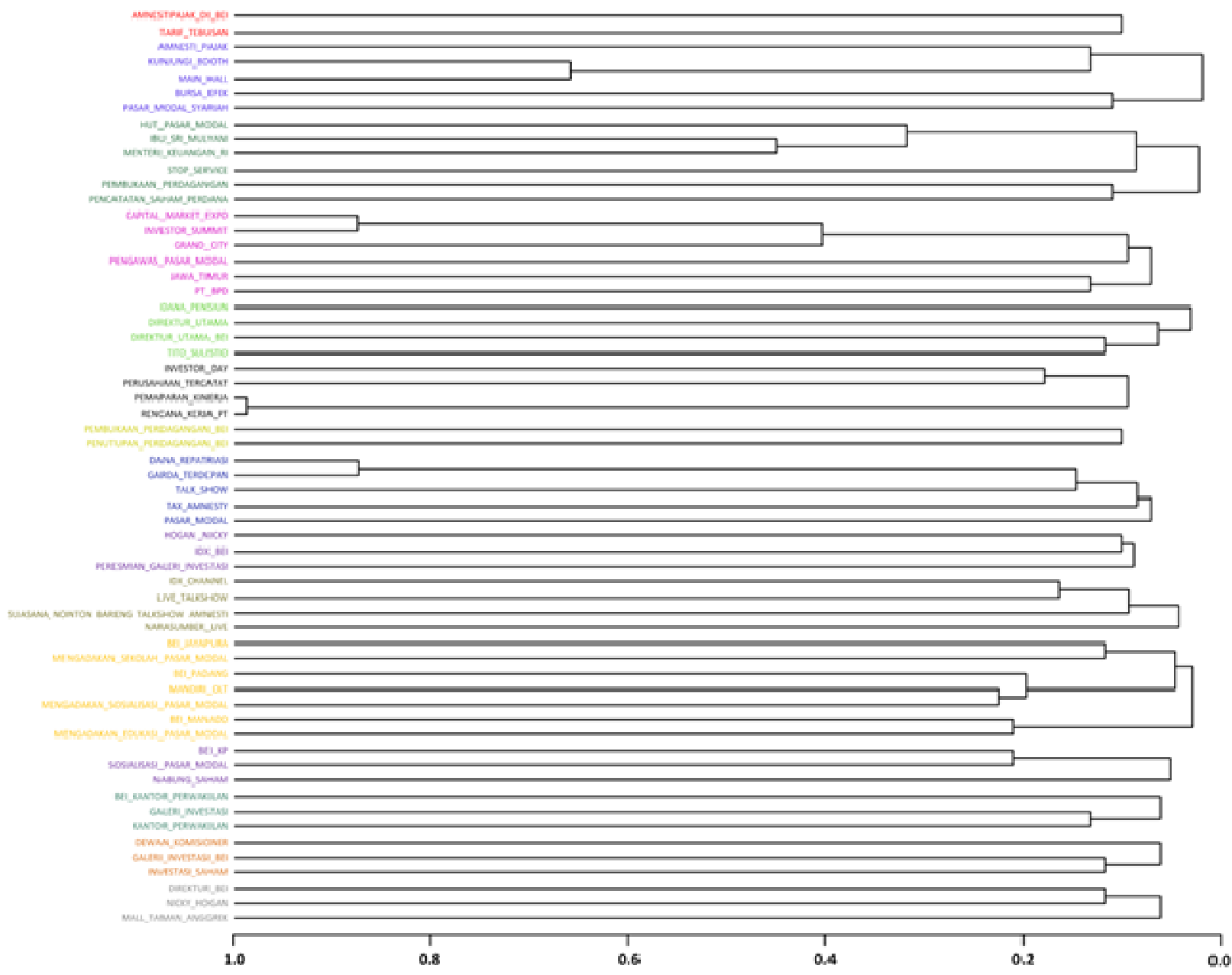

We recommend that@idx_bei can convey optimism and the performance of the stocks in the BEI that affect the sentiment of the stock in BEI. Analysis or reports can be delivered in @idx_bei. Further research conducted by exploring a twitter account in the@idx_bei to obtain the variety of information obtained from @idx_bei. The result has recorded @idx_bei 247,000 follower and account followed by @idx_bei with most follower is Ellen May (206,000) who delivered the analysis about the stocks in Indonesia. Another account that follow@IDX_BEI with a large follower are sucornsekuritas $(28,500)$, Danareksa $(20,500)$, independent 
securities $(18,300)$, Manulife mutual funds $(13,100)$, Samuel securities $(10,800)$. This number indicates that the @Idx BEI follower account is still a few compared with the large number of twitter users in the finalcial industry. That means there are still many communities that have not been keen to follow the account @idx_bei to obtain information regard to the stock market.

In the twitter, @idx bei often post their activities, and rarely post how the development of the current stock, the prospects of the stock market in the days to come, so that the content @idx bei is not delivering useful insights for the stock market.@idx_bei need to increase the community's insights about the stock market, because people will less interested in shares since they have lack of knowledge about the stock so that they don't feel the urgency to make investments in stocks. Efforts to increase the number of communities to invest the stock can be observed from the number of follower of twitter account in the stock market.

@idx_bei need to build marketing communication strategy to improve sentiment towards stocks in Indonesia. For example, enhancing Public Relation \& Publicity which means improving the relationship between the general public with the BEI, by means of holding up-to-date program that can attract the attention of the community towards the investment in shares. Other things that can be done that is changing the appearance of the tweet@idx_bei so that it becomes more attractive with infographics and make the general public interested in reading the content of the twitter, so the number of follower@idx_bei rising.@idx_bei need to deliver current topics about the performance of the JCI, investment funds coming into Indonesia, re-tweet from the stock market analysts about the stocks in Indonesia. Delivering not only the development of the company that will go public, but also the performance of the existing stock in BEI. The attempt to obtain the attributes of the sentiment of the stock market could be developed further by doing a cluster analysis toward twitter accounts followed by (a)idx bei mentioned earlier.

\section{Conclusion}

Activities that are in stock the stock market is closely related to the condition of the economy of a country. This relationship that makes the stock market has many dimensions, from the external dimensions of the stock market that is the condition of the economy, social community and also the environment. There is also the internal dimensions of the stock market which consists of the companies listed, government regulations to regulate stock market activity, in addition there are also institutions institutions that cooperate with the tools to manage Indonesia's stock market. Of the various dimensions of this should have been reflected in the findings of the Exploratory analysis of the stock market@IDX_BEI.

But this study found only a bit of the attribute. This research has discover the attributes of the stock market from@idx_bei, but the result is still minimal because the tweets that were presented in the@idx_bei must only deliver about JCI and IPO. IPO is an example of stock market sentiment which is a form of inter marketing strategy (push strategy). The next process as a follow up of this research is the exploration of the attributes of the sentiment of other twitter accounts that reviews the performance of stocks in Indonesia. This is a push strategy for promoting stocks in Indonesia. In closing the next research need to be done with a longer interval of time again and need to be also carried out exploration against the user that the user is indeed relevant to the Indonesia capital market. Analysis of Exploration results is expected to be more useful and can reflect the realities of the stock market in Indonesia. So the result of this research is not just about celebration of AIPI but can also predict fluctuations in the stock market.

We also propose the need for research to analyze the factors against the stock market from other countries. Through this understanding we may be able to improve the performance of @IDX_BEI marketing communications. So that @IDX_BEI can be a marketing communications channel to promote the stock market in Indonesia.

\section{References}

Al Nasseri, A., Tucker, A., \& de Cesare, S. (2015). Quantifying StockTwits semantic terms' trading behavior in financial markets: An effective application of decision tree algorithms. Expert Systems with Applications, 42(23), 9192-9210.

Byström, H. (2016). Language, news and volatility. Journal of International Financial Markets, Institutions and Money, 42, 139-154. doi:https://doi.org/10.1016/j.intfin.2016.03.002

Chae, B. K. (2015). Insights from hashtag\# supplychain and Twitter Analytics: Considering Twitter and Twitter data for supply chain practice and research. International Journal of Production Economics, 165, 247-259.

Chen, M.-Y., \& Chen, T.-H. (2017). Modeling public mood and emotion: Blog and news sentiment and socioeconomic phenomena. Future Generation Computer Systems. doi:https://doi.org/10.1016/j.future.2017.10.028

Fan, W., \& Gordon, M. D. (2014). The power of social media analytics. Communications of the ACM, 57(6), 7481.

García, A. (2016). Global financial indices and twitter sentiment: A random matrix theory approach. Physica A: 
Statistical Mechanics and its Applications, 461, 509-522. doi:https://doi.org/10.1016/j.physa.2016.06.024

http://thomsonreuters.com. (2014). Thomson Reuters Adds Unique Twitter and News Sentiment Analysis to Thomson Reuters Eikon.

http://www.bloomberg.com. (2014). Trending on twitter social sentiment analytics.

Khanna, B., Moses, S., \& Nirmala, M. (2018). SoftMax based User Attitude Detection Algorithm for Sentimental Analysis. Procedia Computer Science, 125, 313-320.

Kumar, B. S., \& Ravi, V. (2016). A survey of the applications of text mining in financial domain. KnowledgeBased Systems, 114, 128-147.

Lansley, G., \& Longley, P. A. (2016). The geography of Twitter topics in London. Computers, Environment and Urban Systems, 58, 85-96. doi:https://doi.org/10.1016/j.compenvurbsys.2016.04.002

Lewis, R. B., \& Maas, S. M. (2007). QDA Miner 2.0: Mixed-Model Qualitative Data Analysis Software. Field methods, 19(1), 87-108. doi:10.1177/1525822x06296589

Li, Q., Wang, T., Gong, Q., Chen, Y., Lin, Z., \& Song, S.-k. (2014). Media-aware quantitative trading based on public Web information. Decision Support Systems, 61, 93-105. doi:https://doi.org/10.1016/j.dss.2014.01.013

Mazboudi, M., \& Khalil, S. (2017). The attenuation effect of social media: Evidence from acquisitions by large firms. Journal of Financial Stability, 28, 115-124. doi:https://doi.org/10.1016/j.jfs.2016.11.010

Montoyo, A., MartíNez-Barco, P., \& Balahur, A. (2012). Subjectivity and sentiment analysis: An overview of the current state of the area and envisaged developments: Elsevier.

Nugroho, A. (2017). ASEAN Tourism Marketing Communication Attribute: An Exploratory Research at Goaseantv. European Research Studies Journal, XX(3).

Nugroho, A. (2018a). Analisis Faktor Eksploratori Layanan@syariahmandiri. Jurnal Ekonomi, XXIII(3), 376388.

Nugroho, A. (2018b). The Hospitality Marketing Communication Attribute. A Case Study@ @hrhbali (Hard Rock Hotel Bali). Journal of Marketing and Consumer Research, 50.

Nugroho, A., \& Sihite, J. (2015a). Does The Social Network Relate With The Entrepreneurship? An Empirical Content Analysis. Manajemen, XIX(2).

Nugroho, A., \& Sihite, J. (2015b). Is It A Relational Marketing Strategy? Cluster Analysis (a) Universitasmercubuanajakarta Facebook Post and Comment. Manajemen MIX, V(2).

Nugroho, A., \& Sihite, J. (2015c). Is It Traditional or Contemporary Marketing Strategy? A Textual Cluster Analysis@MercuBuana_Reg. Mediterranean Journal of Social Sciences, VI(5).

Nugroho, A., \& Sihite, J. (2015). Tweeting And Retweeting Tourism And Airline Service Attributes. Thomson Reuter Indexed Proceeding. International Geographical Union \& Lombok International Conference. University Mataram.

Nugroho, A., \& Sihite, J. (2016). Exploratory Factor Analysis Syariahmandiri and Bankmandiri Service Attributes 2015. . The Social Sciences, 11, 4896-4901.

Oliveira, N., Cortez, P., \& Areal, N. (2017). The impact of microblogging data for stock market prediction: Using Twitter to predict returns, volatility, trading volume and survey sentiment indices. Expert Systems with Applications, 73, 125-144. doi:https://doi.org/10.1016/j.eswa.2016.12.036

Sihite, J., \& Nugroho, A. (2017). Brand Extension In The Marketspace Journal of Economic \& Management Perspectives, 11(3).

Sihite, J., \& Nugroho, A. (2018). Exploring the Indonesian Tourism Destination via Indonesia.Travel @indtravel.

Silver, C., \& Lewins, A. (2014). Using software in qualitative research: a step-by-step guide.

Tu, W., Yang, M., Cheung, D. W., \& Mamoulis, N. (2018). Investment recommendation by discovering highquality opinions in investor based social networks. Information Systems, 78, 189-198.

Zhang, Y., An, Y., Feng, X., \& Jin, X. (2017). Celebrities and ordinaries in social networks: Who knows more information? Finance Research Letters, 20, 153-161. doi:https://doi.org/10.1016/j.frl.2016.09.021 